\title{
Association of low alanine aminotransferase values with extubation failure in adult critically ill patients: A retrospective cohort study
}

\section{Yoav Weber}

Rambam Medical Center: Rambam Health Care Campus

Danny Epstein ( $\sim$ danyep@gmail.com )

Rambam Health Care Campus https://orcid.org/0000-0001-7032-7007

\section{Asaf Miller}

Rambam Medical Center: Rambam Health Care Campus

\section{Gad Segal}

Sheba Medical Center: Sheba Medical Center at Tel Hashomer

\section{Gidon Berger}

Rambam Medical Center: Rambam Health Care Campus

\section{Research}

Keywords: Alanine aminotransferase, extubation, mechanical ventilation, sarcopenia, weaning,

Posted Date: November 17th, 2020

DOI: https://doi.org/10.21203/rs.3.rs-108276/v1

License: (9) This work is licensed under a Creative Commons Attribution 4.0 International License. Read Full License

Version of Record: A version of this preprint was published at Journal of Clinical Medicine on July 25th, 2021. See the published version at https://doi.org/10.3390/jcm10153282. 


\section{Abstract}

Background: Liberation from mechanical ventilation is a cardinal landmark during hospitalization of ventilated patients in intensive care units. Sufficient respiratory muscle strength and function are essential for successful extubation; therefore, decreased muscle mass and sarcopenia are associated with a high risk of failure. A low level of alanine aminotransferase (ALT) is a known biomarker of sarcopenia. This study was aimed to determine whether low levels of ALT are associated with increased risk of extubation failure among critically ill patients.

Methods: This was a retrospective single-center cohort study of mechanically ventilated patients hospitalized in a medical intensive care unit and undergoing their first extubation. The primary outcome was extubation failure, which was defined as reintubation within seven days. Multivariable logistic regression was performed to determine whether ALT was an independent predictor of this outcome.

Results: The study included 329 patients with a median age of 62.3 years (interquartile range [IQR] 48.13-71.16); $210(63.83 \%)$ patients were at high risk for extubation failure and $83(25.23 \%)$ failed the first extubation attempt. Low ALT values were more common among patients requiring reintubation ( $61.45 \%$ vs. $41.06 \%, P=0.002$ ). Multivariable logistic regression analysis identified the age of 75 years or older and low ALT values as the only independent predictors of extubation failure, with adjusted odds ratio (OR) of 2.74 (95\% confidence interval [Cl] 1.23-6.11, $\mathrm{p}=0.01)$ and $2.14(95 \% \mathrm{Cl} 1.16-3.96, \mathrm{p}=0.02)$, respectively.

Conclusions: Low ALT, an established biomarker of sarcopenia and frailty, is an independent risk factor for extubation failure among adult patients hospitalized in the medical intensive care unit. This simple laboratory parameter can be used as an effective adjunct predictor, along with other weaning parameters, and thereby facilitate the identification of high-risk patients.

\section{Introduction}

Acute respiratory failure is the most common indication for intensive care unit (ICU) admission.(1) Invasive mechanical ventilation (MV) is the cornerstone of management of these patients.(2) Extubation is a crucial moment in the clinical course of many critically ill patients. Despite meeting all predefined criteria and a successful spontaneous breathing trial (SBT), failure of planned extubation still occurs in $10-20 \%$ of cases. Extubation failure is associated with prolonged hospital and ICU stays and increased morbidity and mortality. Studies show that extubation failure and reintubation can directly worsen patient outcomes independently of their underlying morbidity. $(3,4)$

Efficient and rapid strategies for identifying patients at high risk of extubation failure are essential to improve the management of weaning and extubation.(5) Several interventions have been shown to reduce the need for reintubation in this population.(4) These include SBT optimization, performance of additional measurements such as central venous oxygen saturation prior to MV liberation, and usage of post-extubation non-invasive ventilation and/or high-flow nasal oxygen.(4, 6, 7) 
Previous studies have shown that decreased muscle mass and sarcopenia are associated with extubation failure and difficulty in MV liberation. (8-10) These studies evaluated muscle mass using measurement of different skeletal muscle diameter on abdominal computed tomography (CT). However, CT-based analysis of body muscle mass has some prominent limitations such as radiation exposure, high cost, and the need to transport the patient outside of the ICU. Others have suggested using bioelectrical impedance technology for rapid and bedside identification of patients with low body mass. (11) Although promising, this technology is not readily available in most ICUs. Ultrasonographic measurements and dual X-ray absorptiometry have also been used in some clinical trials.(10)

Alanine aminotransferase (ALT), formerly known as serum glutamate-pyruvate transaminase, is a transaminase enzyme found in plasma, muscle tissue, and the liver. It is routinely measured in hospitalized patients as a part of liver panel tests. Generally, high ALT values (> $40 \mathrm{IU} / \mathrm{L}$ ) are considered pathological and reflect liver damage, caused by various mechanisms, such as hepatitis. A low ALT level in the peripheral blood is associated with low muscle mass.(12) Previous studies have demonstrated a correlation between ALT values and muscle mass, as assessed by CT measurements. (13) Recent studies in different clinical fields have shown that low ALT is a reliable biomarker for sarcopenia.(12,14-16)

We hypothesized that low ALT blood levels, a known biomarker for sarcopenia, might also be associated with an increased risk of extubation failure in critically ill medical mechanically ventilated patients.

\section{Methods}

\section{Study design and data sources}

We conducted a population-based retrospective cohort study, using the data of patients hospitalized in an 8-bed medical intensive care unit (MICU) in Rambam Health Care Campus (Rambam) between November 21, 2016 and June 10, 2020. Rambam, located in Haifa, Israel, is a 1,000-bed tertiary academic hospital serving over 2 million residents of the north of the country. According to hospital records, there are 80,000-90,000 inpatient admissions every year.

The study was approved by the Institutional Review Board at RHCC (approval number RMB-499-19). The need for written informed consent was waived due to the retrospective study design.

Data analyzed in this study were retrieved from Prometheus, a proprietary integrated electronic medical records system developed by Rambam. Data were collected from patient files using the MDClone system (Beer-Sheba, Israel). ${ }^{17}$ MDClone system extracts data from electronic medical records, including patient hospitalizations, coded diagnoses, medications, surgical and other procedures, laboratory tests, demographics, and administrative information; all data are presented in a standardized format. The system enables the retrieval of a wide range of variables, for a defined time frame, around an index event. $(17-20)$

\section{Participants}


Orally intubated adult patients hospitalized in Rambam's MICU were eligible for inclusion in the study if their treating senior ICU physician had recorded them as being ready for primary extubation.

Patients were excluded from the study if a primary tracheostomy (without extubation attempt) was performed. Patients who died during the 7-day period after extubation attempt and for whom reintubation was not performed, were also excluded. In addition, patients with end-stage renal disease (ICD10 code N18.6) may have low ALT values not associated with whole-body muscle mass; they were therefore excluded from the study.(21) Subjects with chronic liver diseases (ICD10 codes K70- K77) or elevated ALT value (> $40 \mathrm{IU} / \mathrm{L})$ were also excluded.

Patients were included in the final analysis if ALT measurements were performed during the 10-day period preceding an extubation trial. If several measurements were performed, the lowest value was included in the analysis. In Rambam's MICU, ALT is routinely measured on a daily basis for all patients, Sunday through Thursday, and per special request during the weekends.

\section{Outcome measures and variables}

The primary outcome of this study was successful extubation, defined as not requiring re-intubation for seven days after extubation. All airway management decisions were at the discretion of the treating intensivist. According to local and international guidelines, extubation was performed if the following criteria were fulfilled: the primary cause of respiratory failure was resolved or significantly improved; the patient was able to protect the airway, maintain airway patency, had a strong cough, minimal secretions, had a Glasgow Coma Scale > 8, and was hemodynamically stable (heart rate 60-130 beats per minute; systolic blood pressure $90-185 \mathrm{mmHg}$ ) without or on low-dose vasopressors. Additionally, the following respiratory criteria were considered: positive end-expiratory pressure $\leq 5 \mathrm{cmH}_{2} \mathrm{O}, \mathrm{Pao} 2 / \mathrm{Fio} 2>150$, fiO2 < $50 \%, \mathrm{pH}>7.25$, and a satisfactory rapid shallow breathing index $(<105)$. Spontaneous breathing trial with pressure support ventilation of 5-7 $\mathrm{cmH}_{2} \mathrm{O}$ above positive end-expiratory pressure for 20-30 minutes was routinely performed before extubation. A cuff-leak test was also universally performed before endotracheal tube removal. Application of post-extubation respiratory support with non-invasive ventilation or high flow nasal cannula was at the discretion of the treating clinicians. In our study cohort, all extubations were performed or approved by one of two senior intensivists working in the MICU.

Information on patient demographics, body mass index (BMI), Acute Physiology and Chronic Health Evaluation II (APACHE-II) score, comorbidities, duration of mechanical ventilation prior to extubation trial, and minimal ALT values over the preceding 10 days were collected. As some studies found an association between exposure to corticosteroids, need for red blood cell transfusion, hypoalbuminemia, and hyperglycemia to neuromuscular dysfunction in ICU patients, these data were also collected.(22-25) Time (hours) from extubation to re-intubation was recorded up to seven days after extubation. Prolonged $M V$ was defined as MV exceeding seven days. We defined high-risk extubation patients as those older than 65 years or suffering from any underlying chronic cardiac or lung disease. Underlying chronic cardiac diseases included a history of ischemic heart disease or heart failure. Underlying chronic lung 
diseases included chronic obstructive pulmonary disease. Very high-risk patients were defined as those with two or more risk factors. $(6,26)$

\section{Statistical analysis}

Patient characteristics were summarized with descriptive statistics. Quantitative variables were expressed as means and standard deviations, while qualitative variables were expressed as numbers and percentage. Mean (standard deviation, SD) and median (interquartile range, IQR) were used for the description of normally and non-normally distributed quantitative variables, respectively. Distribution normality was determined using histograms. Univariable analysis was done to assess candidate variables as risk factors for extubation failure, the associations between potential risk factors and the outcome were quantified by the odds ratio $(\mathrm{OR})$ and $95 \%$ confidence interval $(\mathrm{Cl})$. The optimum cutoff for ALT was selected by identifying the value that maximized Youden's $J$ statistic (sum of sensitivity and specificity) on the ROC curve analysis.(27) Multivariate forward stepwise logistic regression was performed to assess the relationship between patient characteristics and extubation failure risk. Variables were selected as candidates for multivariate analysis based on the level of significance of the bivariate association $(P<0.1)$. Multicollinearity between $\mathrm{Ca}^{++}$and all the other independent variables was assessed using the variance inflation factor (VIF). A VIF greater than five was considered suggestive for multicollinearity. Missing data were handled using list-wise deletion. All the available data were used for graphs generation. Cox regression analysis was performed to generate adjusted survival curves according to the ALT categories; $P<0.05$ was considered to be statistically significant.

All available data from Rambam's MICU database within the study time frame were used. To place the available sample size in context, the sample size was estimated. Based on previous reports we estimated that extubation failure could be expected to occur in $20 \%$ of patients.(5) Based on an expected area under the receiver operating characteristic (ROC) curve for ALT of 0.7 , power of $80 \%$, a type I error rate of $5 \%$ (two-sided), and $10 \%$ missing data rates, the calculated sample size was 116 subjects.

Data analysis was conducted with Statistical Package for the Social Sciences, version 23.0 (IBM SPSS Statistics for Windows, Version 23.0. Armonk, NY: IBM Corp) and Microsoft Excel version 14.0 (Microsoft Corporation, Redmond, Washington).

\section{Results}

During the study period, 710 mechanically ventilated patients were hospitalized in Rambam's MICU and considered eligible for extubation by the treating physician. A total of 381 patients were excluded from the analyses: 109 due to chronic medical conditions that may interfere with ALT measurement (ESRD and chronic hepatitis/cirrhosis); 7 patients died during the 7-day period after extubation attempt (without additional intubation); and 265 were excluded due to ALT measurements that were either not performed or which were above $40 \mathrm{IU} / \mathrm{L}$ (Fig. 1). 
The final analyses included 329 patients. Table 1 presents the demographic, clinical, and laboratory characteristics of the study cohort, in relation to outcome. The median study cohort age was 62.3 years (interquartile range [IQR] 48.1-71.2), of which $56(17 \%)$ were 75 years old or older. Most of the patients were male $(n=205 ; 62.4 \%)$. The mean APACHE-II score for the cohort was high, 27.8 (SD 6.5) points, indicating that 210 patients $(63.8 \%)$ were at high risk of extubation failure and $144(43.8 \%)$ at very high risk. 
Table 1

Demographic, clinical and laboratory characteristics in relation to outcome

\begin{tabular}{|c|c|c|c|c|c|}
\hline Characteristic & $\begin{array}{l}\text { Total } \\
(n= \\
329)\end{array}$ & $\begin{array}{l}\text { Failed } \\
\text { extubation } \\
(n=83)\end{array}$ & $\begin{array}{l}\text { Successful } \\
\text { extubation } \\
(\mathrm{n}=\mathbf{2 4 6})\end{array}$ & $\begin{array}{l}\text { OR } \\
(95 \% \\
\text { Cl) }\end{array}$ & $\begin{array}{l}P \\
\text { value }\end{array}$ \\
\hline Age, years (IQR) & $\begin{array}{l}62.4 \\
(48- \\
71.2)\end{array}$ & $\begin{array}{l}65.7(55- \\
76.2)\end{array}$ & $\begin{array}{l}62.1 \\
(45.7-70)\end{array}$ & $\begin{array}{l}1(1- \\
1.04)\end{array}$ & 0.013 \\
\hline Elderly ( $\geq 75$ years), n (\%) & $\begin{array}{l}56 \\
(17 \%)\end{array}$ & $\begin{array}{l}25 \\
(30.12 \%)\end{array}$ & $31(12.6 \%)$ & $\begin{array}{l}2.99 \\
(1.64- \\
5.45)\end{array}$ & $<0.001$ \\
\hline Male gender, n (\%) & $\begin{array}{l}205 \\
(62.3 \%)\end{array}$ & $\begin{array}{l}45 \\
(54.2 \%)\end{array}$ & $160(65 \%)$ & $\begin{array}{l}0.64 \\
(0.38- \\
1.05)\end{array}$ & 0.08 \\
\hline $\mathrm{BMI}, \mathrm{kg} / \mathrm{m}^{2}(\mathrm{IQR})$ & $\begin{array}{l}26.85 \\
(23.5- \\
31)\end{array}$ & $\begin{array}{l}27.5 \\
(24.2- \\
30.9)\end{array}$ & $\begin{array}{l}26.2(23.4- \\
31.03)\end{array}$ & $\begin{array}{l}1.01 \\
(0.97- \\
1.05)\end{array}$ & 0.73 \\
\hline APACHE-II score (SD) ${ }^{*}$ & $\begin{array}{l}27.83 \\
(6.47)\end{array}$ & $\begin{array}{l}29.29 \\
(6.66)\end{array}$ & $\begin{array}{l}27.24 \\
(6.31)\end{array}$ & $\begin{array}{l}1.05(1- \\
1.1)\end{array}$ & 0.03 \\
\hline $\begin{array}{l}\text { Prolonged mechanical ventilation }(>7 d) \text {, } \\
n(\%)\end{array}$ & $\begin{array}{l}65 \\
(19.8 \%)\end{array}$ & $\begin{array}{l}14 \\
(16.9 \%)\end{array}$ & $51(20.7 \%)$ & $\begin{array}{l}0.78 \\
(0.4- \\
1.5)\end{array}$ & 0.44 \\
\hline $\begin{array}{l}\text { Corticosteroids treatment during } \\
\text { preceding } 7 \text { days, } \mathrm{n}(\%)\end{array}$ & $\begin{array}{l}113 \\
(34.4 \%)\end{array}$ & $\begin{array}{l}32 \\
(38.6 \%)\end{array}$ & $81(32.9 \%)$ & $\begin{array}{l}1.28 \\
(0.76- \\
2.14)\end{array}$ & 0.35 \\
\hline $\begin{array}{l}\text { Blood transfusion during preceding } 60 \\
\text { days, } \mathrm{n}(\%)\end{array}$ & $\begin{array}{l}54 \\
(16.4 \%)\end{array}$ & $\begin{array}{l}14 \\
(16.9 \%)\end{array}$ & $40(16.3 \%)$ & $\begin{array}{l}1.04 \\
(0.54- \\
2.04)\end{array}$ & 0.9 \\
\hline $\begin{array}{l}\text { 30-day mortality (after extubation } \\
\text { attempt), n (\%) }\end{array}$ & $\begin{array}{l}28 \\
(8.5 \%)\end{array}$ & $\begin{array}{l}15 \\
(18.1 \%)\end{array}$ & $13(5.3 \%)$ & $\begin{array}{l}3.95 \\
(1.79- \\
8.71)\end{array}$ & $\dot{0} 001$ \\
\hline \multicolumn{6}{|l|}{ Comorbidities } \\
\hline DM, n (\%) & $\begin{array}{l}113 \\
(34.4 \%)\end{array}$ & $\begin{array}{l}35 \\
(42.2 \%)\end{array}$ & $78(31.7 \%)$ & $\begin{array}{l}1.57 \\
(0.94- \\
2.62)\end{array}$ & 0.09 \\
\hline
\end{tabular}

* APACHE-II score was recorded in 239 cases (72.6\%)

ALT, Alanine transaminase; APACHE-Il score, Acute Physiology and Chronic Health Evaluation II; BMI, body mass index; $\mathrm{CHF}$, congestive heart failure; $\mathrm{Cl}$, confidence interval; $\mathrm{CKD}$, chronic kidney disease; COPD, chronic obstructive lung disease; CVA, cerebrovascular disease; DM, diabetes mellitus; HTN, hypertension; IHD, ischemic heart disease; IQR, interquartile range; OR, odds ratio; SD, standard deviation. 


\begin{tabular}{|c|c|c|c|c|c|}
\hline Characteristic & $\begin{array}{l}\text { Total } \\
(n= \\
329)\end{array}$ & $\begin{array}{l}\text { Failed } \\
\text { extubation } \\
(n=83)\end{array}$ & $\begin{array}{l}\text { Successful } \\
\text { extubation } \\
(n=246)\end{array}$ & $\begin{array}{l}\text { OR } \\
\text { (95\% } \\
\text { Cl) }\end{array}$ & $\begin{array}{l}P \\
\text { value }\end{array}$ \\
\hline CKD, n (\%) & $\begin{array}{l}54 \\
(16.4 \%)\end{array}$ & $\begin{array}{l}14 \\
(16.9 \%)\end{array}$ & $40(16.3 \%)$ & $\begin{array}{l}1.04 \\
(0.54- \\
2.04)\end{array}$ & 0.89 \\
\hline CHF, n (\%) & $\begin{array}{l}89 \\
(27.1 \%)\end{array}$ & $\begin{array}{l}26 \\
(31.3 \%)\end{array}$ & $63(25.6 \%)$ & $\begin{array}{l}1.33 \\
(0.77- \\
2.29)\end{array}$ & 0.32 \\
\hline CVD, n (\%) & $\begin{array}{l}52 \\
(15.8 \%)\end{array}$ & $\begin{array}{l}15 \\
(18.1 \%)\end{array}$ & $37(15 \%)$ & $\begin{array}{l}1.25 \\
(0.64- \\
2.41)\end{array}$ & 0.52 \\
\hline COPD, n (\%) & $\begin{array}{l}75 \\
(22.8 \%)\end{array}$ & $\begin{array}{l}14 \\
(16.9 \%)\end{array}$ & $61(24.1 \%)$ & $\begin{array}{l}0.62 \\
(0.32- \\
1.17)\end{array}$ & 0.13 \\
\hline HTN, n (\%) & $\begin{array}{l}171 \\
(52 \%)\end{array}$ & $\begin{array}{l}48 \\
(57.3 \%)\end{array}$ & $123(50 \%)$ & $\begin{array}{l}1.37 \\
(0.83- \\
2.27)\end{array}$ & 0.22 \\
\hline IHD, n (\%) & $\begin{array}{l}74 \\
(22.5 \%)\end{array}$ & $\begin{array}{l}26 \\
(31.3 \%)\end{array}$ & $48(19.5 \%)$ & $\begin{array}{l}1.88 \\
(1.07- \\
3.3)\end{array}$ & 0.03 \\
\hline High risk of extubation failure, $\mathrm{n}(\%)$ & $\begin{array}{l}210 \\
(63.8 \%)\end{array}$ & $\begin{array}{l}58 \\
(69.9 \%)\end{array}$ & $\begin{array}{l}152 \\
(61.8 \%)\end{array}$ & $\begin{array}{l}1.43 \\
(0.84- \\
1.75)\end{array}$ & 0.18 \\
\hline Very high risk of extubation failure, $\mathrm{n}(\%)$ & $\begin{array}{l}144 \\
(43.8 \%)\end{array}$ & $\begin{array}{l}41 \\
(49.4 \%)\end{array}$ & $\begin{array}{l}103 \\
(41.9 \%)\end{array}$ & $\begin{array}{l}1.36 \\
(0.82- \\
2.23)\end{array}$ & 0.23 \\
\hline \multicolumn{6}{|l|}{$\begin{array}{l}\text { Laboratory values (worse value during } \\
\text { preceding } 10 \text { days) }\end{array}$} \\
\hline Hypoalbuminemia (<3.5 g/dL), n (\%) & $\begin{array}{l}278 \\
(84.5 \%)\end{array}$ & $\begin{array}{l}74 \\
(89.2 \%)\end{array}$ & $\begin{array}{l}204 \\
(82.9 \%)\end{array}$ & $\begin{array}{l}1.15 \\
(0.69- \\
1.92)\end{array}$ & 0.59 \\
\hline Low ALT (<17 IU/L), n (\%) & $\begin{array}{l}152 \\
(46.2 \%)\end{array}$ & $\begin{array}{l}51 \\
(61.5 \%)\end{array}$ & $\begin{array}{l}101 \\
(41.1 \%)\end{array}$ & $\begin{array}{l}2.29 \\
(1.37- \\
3.81)\end{array}$ & 0.001 \\
\hline
\end{tabular}

* APACHE-II score was recorded in 239 cases (72.6\%)

ALT, Alanine transaminase; APACHE-II score, Acute Physiology and Chronic Health Evaluation II; BMI, body mass index; $\mathrm{CHF}$, congestive heart failure; $\mathrm{Cl}$, confidence interval; $\mathrm{CKD}$, chronic kidney disease; COPD, chronic obstructive lung disease; CVA, cerebrovascular disease; DM, diabetes mellitus; HTN, hypertension; IHD, ischemic heart disease; IQR, interquartile range; OR, odds ratio; SD, standard deviation. 


\begin{tabular}{|c|c|c|c|c|c|}
\hline Characteristic & $\begin{array}{l}\text { Total } \\
(\mathrm{n}= \\
329)\end{array}$ & $\begin{array}{l}\text { Failed } \\
\text { extubation } \\
(n=83)\end{array}$ & $\begin{array}{l}\text { Successful } \\
\text { extubation } \\
(n=246)\end{array}$ & $\begin{array}{l}\text { OR } \\
(95 \% \\
\mathrm{Cl})\end{array}$ & $\begin{array}{l}P \\
\text { value }\end{array}$ \\
\hline $\begin{array}{l}\text { Hyperglycemia (> }>180 \mathrm{mg} / \mathrm{dL} \text { ) during } \\
48 \mathrm{~h} \text { preceding extubation trial, } \mathrm{n}(\%)\end{array}$ & $\begin{array}{l}198 \\
(60.2 \%)\end{array}$ & $\begin{array}{l}52 \\
(62.7 \%)\end{array}$ & $\begin{array}{l}146 \\
(59.4 \%)\end{array}$ & $\begin{array}{l}1.15 \\
(0.69- \\
1.92)\end{array}$ & 0.59 \\
\hline \multicolumn{6}{|c|}{ * APACHE-II score was recorded in 239 cases (72.6\%) } \\
\hline \multicolumn{6}{|c|}{$\begin{array}{l}\text { ALT, Alanine transaminase; APACHE-II score, Acute Physiology and Chronic Health Evaluation II; BMI, } \\
\text { body mass index; CHF, congestive heart failure; Cl, confidence interval; CKD, chronic kidney disease; } \\
\text { COPD, chronic obstructive lung disease; CVA, cerebrovascular disease; DM, diabetes mellitus; HTN, } \\
\text { hypertension; IHD, ischemic heart disease; IQR, interquartile range; OR, odds ratio; SD, standard } \\
\text { deviation. }\end{array}$} \\
\hline
\end{tabular}

During the seven-day follow-up, 83 patients $(25.2 \%)$ failed an extubation trial and were re-intubated. Using ROC curve analysis, we determined the optimal cutoff point for ALT and extubation failure. The optimal ALT value was $17 \mathrm{IU} / \mathrm{L}$ (AUC $0.6 ; 95 \% \mathrm{Cl} 0.55-0.66 ; P=0.002$ ).

Low ALT was recorded among 51 (61.5\%) of patients with failed extubation compared to 101 (41.1\%) in the successfully extubated group $(P=0.002)$. Fifty-one of $152(33.5 \%)$ patients with ALT below $17 \mathrm{IU} / \mathrm{L}$ failed the extubation trial, while only 32 of $177(18.1 \%)$ patients with a higher ALT failed it $(P=0.003)$.

Multivariable logistic regression analysis identified the age of 75 years or older and low ALT as the only independent predictors of the need for re-intubation, with adjusted ORs of 2.74 (95\% Cl 1.23-6.11, p = $0.01)$ and $2.14(95 \% \mathrm{Cl} 1.16-3.96, \mathrm{p}=0.02)$, respectively. The results of multivariable regression analysis are presented in Table 2. We used the Cox regression model to generate adjusted survival curves for each ALT subgroup, $(p<0.001)$, Fig. 2 . The relationship between ALT and age subgroups is shown in Fig. 3 .

Table 2

Results of multivariable logistic regression analysis.

\begin{tabular}{|lll|}
\hline & OR $(95 \%$ Cl) & $P$ value \\
\hline Elderly $(\geq 75$ years $)$ & $2.74(1.23-6.11)$ & 0.01 \\
\hline Male gender & $0.54(0.29-1)$ & 0.05 \\
\hline APACHE-Il score (SD)* & $1(0.95-1.06)$ & 0.93 \\
\hline Diabetes mellitus & $1.39(0.7-2.75)$ & 0.35 \\
\hline Ischemic heart disease & $1.92(0.89-4.14)$ & 0.1 \\
\hline Low ALT $(<17$ IU/L) & $2.14(1.16-3.96)$ & 0.02 \\
\hline
\end{tabular}


Since all the VIF values were lower than 5 , we confirmed the absence of multicollinearity.

* APACHE-II score was recorded in 239 cases (72.64\%).

ALT, alanine transaminase; APACHE-II score, Acute Physiology and Chronic Health Evaluation Il; OR, odds ratio; $\mathrm{Cl}$, confidence interval.

\section{Discussion}

This retrospective study found that low ALT values were independently associated with a higher risk of first attempt extubation failure among, critically ill patients hospitalized in medical ICU.

Sarcopenia is defined as low muscle mass, strength, and function. It can occur because of normal aging or secondary to severe illness, malnutrition, or low activity level.(28) As severe illness and malnutrition are commonly found in ICU patients, the prevalence of sarcopenia in this population is very high.(9) ICU related sarcopenia is usually a result of critical illness neuromyopathy; although it primarily affects the lower limbs, it is associated with respiratory muscle and diaphragm weakness.(10) Studies have reported that up to $100 \%$ of ICU patients with multi-organ failure develop muscle mass loss during hospitalization. (29) Other studies have found that elderly patients lost $10 \%$ of total body muscle mass during only three days of immobility, while one week of complete bed rest is associated with $>10 \%$ reduction in postural muscle strength in healthy subjects.(10) Respiratory muscle mass loss also develops very quickly; diaphragm wasting is seen as soon as 24 hours after intubation and diaphragm thickness decreases by 3-6\% every 24 hours of MV.(30,31) Major risk factors for ICU related sarcopenia include primary disease severity, and length of MV and ICU stay. Some studies found that older age, female gender, administration of corticosteroids and neuromuscular blockers, need for red blood cell transfusion, hypoalbuminemia, and hyperglycemia are also possible risk factors.(10, 22-25)

Since normal function and mass of the respiratory musculature is required for initiation of an inspiratory effort and the ability to maintain spontaneous breathing, it is not surprising that diaphragmatic and other respiratory muscle atrophy and weakness are associated with difficulty in weaning from MV. The association between sarcopenia and extubation failure was recently evaluated by Woo and colleagues. ${ }^{9}$ In adult Korean patients with prolonged (more than seven days) MV, sarcopenia, as assessed by L3 skeletal muscle index on abdominal CT, was associated with extubation failure (OR of $24.38,95 \% \mathrm{Cl} 1$ 594.86).(9) Using the same method of sarcopenia assessment, Kou et al. found that sarcopenia was associated with prolonged weaning (more than seven days of weaning after the first SBT) or need for reintubation within 48 hours after extubation in critically ill surgical patients in Taiwan.(8)

There is no gold standard for sarcopenia assessment in the ICU. Although muscle mass can be measured by either bioelectrical impedance, dual X-ray absorptiometry, $\mathrm{CT}$, magnetic resonance imaging, and ultrasonography, all these methods are preliminary research tools; their bedside and routine use is complex in ICU settings and limited to clinical trials.(10) 
ALT, measured in almost every routine blood test, is a surrogate marker for low general body muscle mass and sarcopenia. $(13,16)$ It was recently shown that low ALT levels are associated with reduced muscle strength, adverse outcomes in the general population of hospitalized patients, patients with chronic obstructive pulmonary disease exacerbation, and rehabilitation program participants. $(12,15,16,32)$ To the best of our knowledge, this is the first study to assess the correlation between low ALT and extubation failure.

This study retrospectively included all medically critically ill patients who fulfilled all clinical and laboratory criteria for extubation and successfully passed SBT. In this heterogenic group, only age over 75 years and low ALT were associated with extubation failure. Based on the existing evidence, we believe that this association is explained by the extremely low muscle mass of patients with ALT levels below $17 \mathrm{IU} / \mathrm{L}$.

In the literature, extubation failure is defined as an inability to sustain spontaneous breathing after extubation within a specified period: from 24-72 hours and up to seven days.(33) We extended our follow up to seven days; however, as demonstrated in Fig. 2, the differences between the ALT groups are already evident a few hours after extubation. In our cohort, the seven-day extubation failure rate was $25 \%$; this high rate can be explained by the high-risk population included in the cohort ( $63.8 \%$ had a high risk of failure; $43.8 \%$ had a very high risk). The previously reported reintubation rates in these groups is between $20-30 \%$, or even higher.(26)

Our study has some limitations. First, this was a retrospective study with relatively small sample size. Second, we did not include ventilation indexes (such as peak pressure, respiratory rate, rapid shallow breathing index) before an extubation attempt. However, all patients in the cohort were considered suitable for extubation by two senior physicians according to local and international guidelines. Third, only patients with available and normal serum ALT levels were included. This test was performed at the discretion of the treating physician, as part of routine chemistry analysis, rather than systematically. The usage of ALT as a surrogate of sarcopenia and its ability to predict extubation outcome is limited to patients with low ALT; however, some sarcopenic patients may have elevated ALT due to hepatic damage which is not uncommon in critically ill patients. Fourth, we did not include the etiology of respiratory failure in the analysis but rather used an unselected cohort of all critically ill medical patients. Fifth, no information was available regarding administration of muscle relaxants, which can facilitate muscle wasting in critically ill patients.

\section{Conclusion}

Low ALT values are significantly associated with extubation failure, and should be flagged in ventilated patients prior to extubation. Looking at the ALT values in addition to the evaluation of other objective clinical criteria could aid the clinician in making a more comprehensive, personalized, and informed decision regarding mechanical ventilation weaning and planning patient management after extubation. 


\section{List Of Abbreviations}

ALT, alanine aminotransferase

APACHE-II score, Acute Physiology and Chronic Health Evaluation II

$\mathrm{CT}$, computed tomography

ICU, intensive care unit

IQR, interquartile range

MICU, medical intensive care unit

MV, mechanical ventilation;

OR, odds ratio;

Rambam, Rambam Health Care Campus;

ROC, receiver operating characteristic;

SBT, spontaneous breathing trial;

VIF, variance inflation factor

\section{Declarations}

Ethics approval and consent to participate

This was not a clinical study and did not require registration.

This study was approved by the Institutional Review Board of Rambam Health Care Campus, approval number RMB-499-19. The need for written informed consent was waived due to the retrospective study design.

Consent for publication: Not applicable.

Availability of data and materials: The datasets used and/or analyzed during the current study are available from the corresponding author on reasonable request.

Competing interests

The authors declare that they have no competing interests

Funding

Page 12/18 
Not applicable.

Authors' contributions

YW conceived the idea for the study, designed the study, analyzed the data, and drafted the manuscript. YW and DE contributed equally as first authors.

DE conceived the idea for the study, designed the study, analyzed the data, performed the statistical analysis, and drafted the manuscript. YW and DE contributed equally as first authors.

AM conceived the idea for the study, designed the study, drafted the manuscript, and approved the final manuscript as submitted.

GS conceived the idea for the study, designed the study, critically reviewed, and revised the manuscript, and approved the final manuscript as submitted.

GB conceived the idea for the study, designed the study, critically reviewed, and revised the manuscript, and approved the final manuscript as submitted.

Acknowledgements

The authors wish to acknowledgement of Mrs. Deborah Hemstreet for English editing and preparation of the manuscript for submission.

\section{References}

1. Lai CC, Tseng KL, Ho CH, Chiang SR, Chen CM, Chan KS, et al. Prognosis of patients with acute respiratory failure and prolonged intensive care unit stay. J Thorac Dis. 2019;11(5):2051-7.

2. Slutsky AS. History of Mechanical Ventilation. From Vesalius to Ventilator-induced Lung Injury. Am J Respir Crit Care Med. 2015;191(10):1106-15.

3. Thille AW, Cortés-Puch I, Esteban A. Weaning from the ventilator and extubation in ICU. Curr Opin Crit Care. 2013;19(1):57-64.

4. Jeganathan N, Kaplan CA, Balk RA. Ventilator liberation for high-risk-for-failure patients: Improving value of the spontaneous breathing trial. Respir Care. 2015 Feb 1;60(2):290-6.

5. Thille AW, Richard JCM, Brochard L. The decision to extubate in the intensive care unit. Am J Respir Crit Care Med. 2013;187(12):1294-302.

6. Thille AW, Muller G, Gacouin A, Coudroy R, Decavèle M, Sonneville R, et al. Effect of Postextubation High-Flow Nasal Oxygen with Noninvasive Ventilation vs High-Flow Nasal Oxygen Alone on Reintubation among Patients at High Risk of Extubation Failure: A Randomized Clinical Trial. JAMA. 2019;322(15):1465-75.

7. Yeung J, Couper K, Ryan EG, Gates S, Hart N, Perkins GD. Non-invasive ventilation as a strategy for weaning from invasive mechanical ventilation: a systematic review and Bayesian meta-analysis. 
Intensive Care Med. 2018;44(12):2192-204.

8. Kou HW, Yeh CH, Tsai H, Hsu CC, Hsieh YC, Chen WT, et al. Sarcopenia is an effective predictor of difficult-to-wean and mortality among critically ill surgical patients. PLoS One. 2019;14(8).

9. Woo HY, Oh SY, Lee H, Ryu HG. Evaluation of the association between decreased skeletal muscle mass and extubation failure after long-term mechanical ventilation. Clin Nutr. 2020;39(9):2764-70.

10. Kizilarslanoglu MC, Mehmet ·, Kuyumcu E, Yesil Y. Halil · Meltem. Sarcopenia in critically ill patients. J Anesth. 2016;30:884-90.

11. Looijaard WGPM, Stapel SN, Dekker IM, Rusticus H, Remmelzwaal S, Girbes ARJ, et al. Identifying critically ill patients with low muscle mass: Agreement between bioelectrical impedance analysis and computed tomography. Clin Nutr. 2019;39(6).

12. Lasman N, Shalom M, Turpashvili N, Goldhaber G, Lifshitz Y, Leibowitz E, et al. Baseline low ALT activity is associated with increased long-term mortality after COPD exacerbations. BMC Pulm Med. 2020;20(133).

13. Portal D, Hofstetter L, Eshed I, Dan Lantsman C, Sella T, Urban D, et al. L3 skeletal muscle index (L3SMI) is a surrogate marker of sarcopenia and frailty in non-small cell lung cancer patients. Cancer Manag Res. 2019 Apr 1;11:2579-88.

14. Vespasiani-Gentilucci U, De Vincentis A, Ferrucci L, Bandinelli S, Antonelli Incalzi R, Picardi A. Low Alanine Aminotransferase Levels in the Elderly Population: Frailty, Disability, Sarcopenia, and Reduced Survival. Journals Gerontol - Ser A Biol Sci Med Sci. 2018;73(7):925-30.

15. Kogan M, Klempfner R, Lotan D, Wasserstrum Y, Goldenberg I, Segal G. Low ALT blood levels are associated with lower baseline fitness amongst participants of a cardiac rehabilitation program. J Exerc Sci Fit. 2018;16(1):1-4.

16. Itelman E, Segev A, Ahmead L, Leibowitz E, Agbaria M, Avaky C, et al. Low ALT Values amongst Hospitalized Patients are Associated with Increased Risk of Hypoglycemia and Overall Mortality. A Retrospective, Big-data Analysis of 51,831 Patients. QJM. 2020 Jul.

17. Reiner Benaim A, Almog R, Gorelik Y, Hochberg I, Nassar L, Mashiach T, et al. Analyzing Medical Research Results Based on Synthetic Data and Their Relation to Real Data Results: Systematic Comparison From Five Observational Studies. JMIR Med Informatics. 2020;8(2):e16492.

18. Hochberg I. Insulin Detemir Use Is Associated with Higher Occurrence of Hypoglycemia in Hospitalized Patients with Hypoalbuminemia. Diabetes Care. 2018;41(4):e44-6.

19. Gorelik Y, Yaseen H, Heyman SN, Khamaisi M. Negligible Risk of Acute Renal Failure Among Hospitalized Patients After Contrast-Enhanced Imaging With lodinated Versus Gadolinium-Based Agents. Invest Radiol. 2019;54(5):312-8.

20. Even dar R, Kurnik D, Bishop B, Bogner I, Azzam Z, Paul M, et al. Are corticosteroids or end-stage renal failure associated with afebrile presentation of Gram-negative bacteremia? Int J Antimicrob Agents. 2020;56(3):106070.

21. Dagan A, Sella T, Urban D, Bar Y, Onn A, Segal G. Low alanine transaminase is not associated with increased rate of mortality in patients with advanced lung cancer. JCSM Clin Reports. 2017;2(1):1-5. 
22. De Jonghe B, Sharshar T, Lefaucheur JP, Authier FJ, Durand-Zaleski I, Boussarsar M, et al. Paresis acquired in the intensive care unit: A prospective multicenter study. J Am Med Assoc. 2002;288(22):2859-67.

23. Khalil Y, Mustafa EED, Youssef A, Imam MH, Behiry AF, El. Neuromuscular dysfunction associated with delayed weaning from mechanical ventilation in patients with respiratory failure. Alexandria $J$ Med. 2012;48(3):223-32.

24. Hafner $S$, Radermacher $P$, Frick $M$, Dietl $P$, Calzia E. Hyperglycemia, oxidative stress, and the diaphragm: A link between chronic co-morbidity and acute stress? Crit Care. 2014;18(3):149.

25. Parsons EC, Kross EK, Ali NA, Vandevusse LK, Caldwell ES, Watkins TR, et al. Red blood cell transfusion is associated with decreased in-hospital muscle strength among critically ill patients requiring mechanical ventilation. J Crit Care. 2013;28(6):1079-85.

26. Thille AW, Boissier F, Ben-Ghezala H, Razazi K, Mekontso-Dessap A, Brun-Buisson C, et al. Easily identified at-risk patients for extubation failure may benefit from noninvasive ventilation: $A$ prospective before-after study. Crit Care. 2016;20(1).

27. Youden WJ. Index for rating diagnostic tests. Cancer. 1950 Jan 1;3(1):32-5.

28. Janssen I. The epidemiology of sarcopenia. Clin Geriatr Med. 2011;27(3):355-63.

29. Van Mook WNKA, Hulsewé-Evers RPMG. Critical illness polyneuropathy. Curr Opin Crit Care. 2002;8(4):302-10.

30. Levine S, Nguyen T, Taylor N, Friscia ME, Budak MT, Rothenberg P, et al. Rapid disuse atrophy of diaphragm fibers in mechanically ventilated humans. N Engl J Med. 2008;358(13):1327-35.

31. Jaber S, Petrof BJ, Jung B, Chanques G, Berthet JP, Rabuel C, et al. Rapidly progressive diaphragmatic weakness and injury during mechanical ventilation in humans. Am J Respir Crit Care Med. 2011;183(3):364-71.

32. Chung SM, Moon JS, Yoon JS, Won KC, Lee HW. Low alanine aminotransferase levels predict low muscle strength in older patients with diabetes: A nationwide cross-sectional study in Korea. Geriatr Gerontol Int. 2020;20(4):271-6.

33. Epstein SK, Ciubotaru RL, Wong JB. Effect of failed extubation on the outcome of mechanical ventilation. Chest. 1997;112(1):186-92.

\section{Figures}




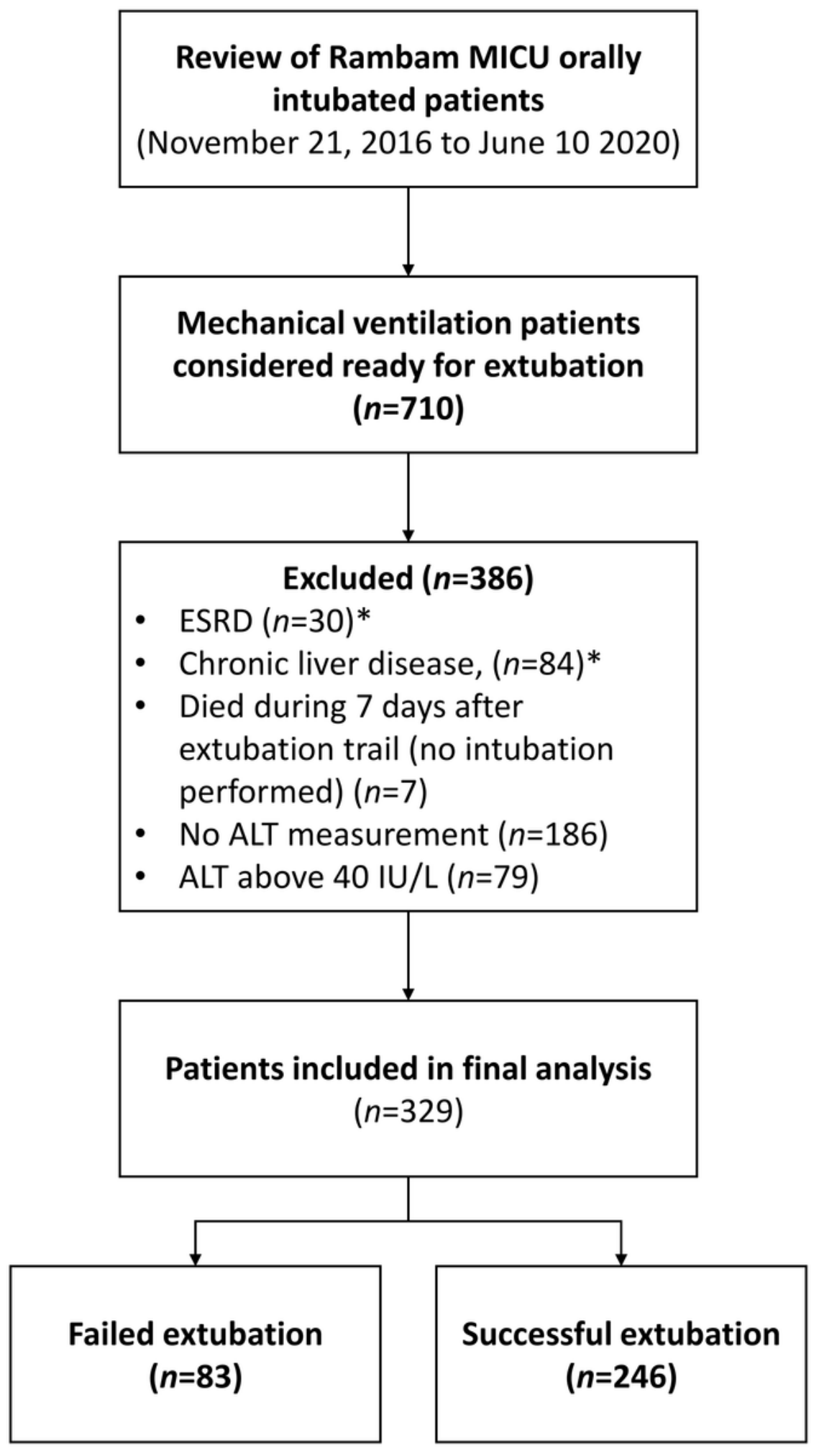

Figure 1

Study flow chart. * 5 patients suffered from both ESRD and chronic liver disease. ALT, alanine transaminase; ESRD, end-stage renal disease; MICU, medical intensive care unit; Rambam, Rambam Health Care Campus. 


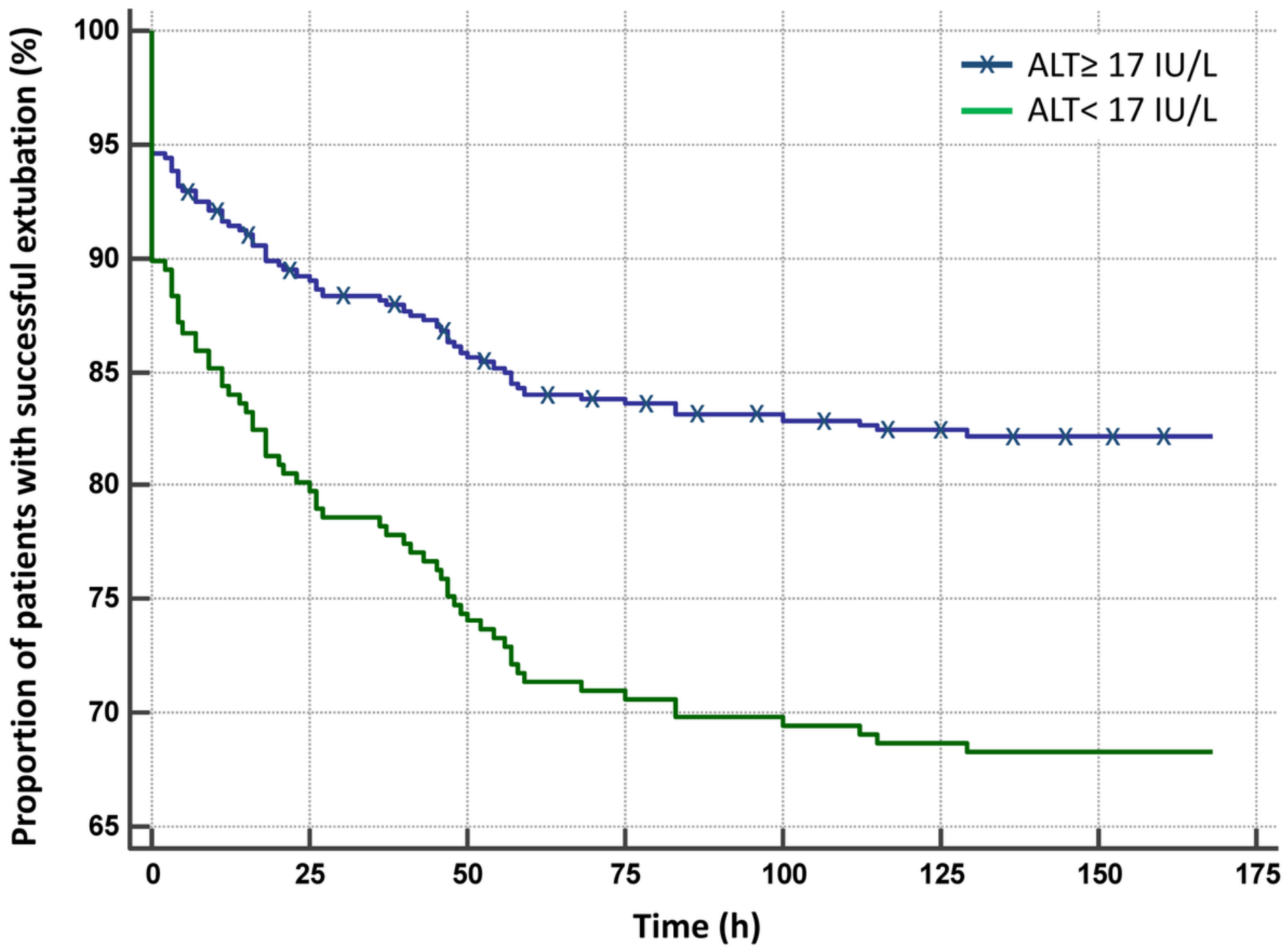

Figure 2

Survival curve for 7-days extubation failure according to the lowest ALT value during 10 days preceding extubation trial, adjusted to age $(p<0.001)$. ALT, Alanine transaminase. 


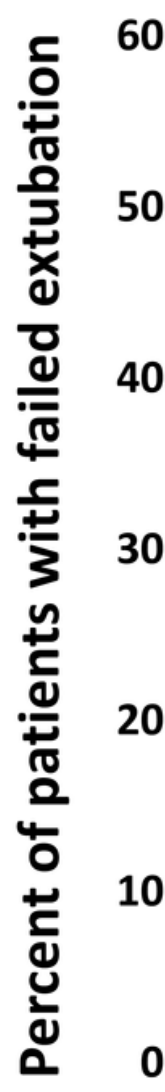

$P=0.15$

50

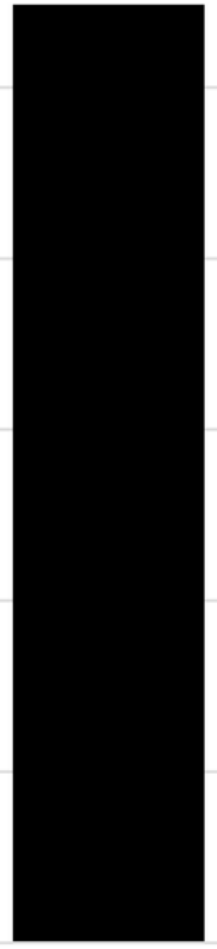

Age $<75$

Age $\geq 75$

$\square$ ALT $<17$ IU/L $\quad$ ALT $\geq 17$ IU/L

Figure 3

The relationship between ALT, age, and the risk of 7-day extubation failure. ALT, alanine transaminase. 